\title{
Code-switching in multilinguals with dementia: Patterns across speech contexts
}

\author{
Jan Svennevig ${ }^{\mathrm{a}}$, Pernille Hansen ${ }^{\mathrm{a}}$, Hanne Gram Simonsen ${ }^{\mathrm{a}}$ and \\ Anne Marie Dalby Landmark ${ }^{a}$ \\ a University of Oslo Faculty of Humanities, Center for Multilingualism in Society \\ across the Lifespan
}

*perniha@uio.no

The study investigates code-switching by multilingual persons with dementia in two different speech contexts, picture naming tests and spontaneous conversation. It combines a psycholinguistic perspective on cognitive and linguistic skills with a qualitative conversation analytic approach to understanding the functions and appropriateness of code-switching in social interaction. The analysis shows that code-switching is used as a resource for compensating for word-retrieval problems in both the naming tests and in word search sequences in conversation. Furthermore, it serves to demarcate metacommunicative parentheses in which the participants comment on their process of word retrieval or express frustration about processing problems. Code-switching is generally treated as appropriate and relevant by the participants. In most instances, the speakers switch to a language known by the interlocutor. Only a few instances are treated as inappropriate by not being understandable to the interlocutor or by not adapting to the established language of the conversation. The patterns of code-switching are discussed considering typical symptoms of cognitive decline associated with dementia. Only very few instances may be interpreted as caused by a lack of awareness of the interlocutor's language background (associated with reduced episodic memory) or a lack of inhibition. Code-switching thereby presents itself primarily as a communicative resource for handling and overcoming another dementia-related symptom, namely anomia.

Keywords: dementia, code-switching, conversation analysis, multilingualism, psycholinguistics 
Multilinguals use their full linguistic competence in communication with others. Their natural linguistic behaviour includes both monolingual conversations and codeswitching, which may be defined as the practice of alternating between two or more languages or varieties during a conversation (Grosjean, 1989, 2008). Code-switching may be treated as appropriate or inappropriate by the participants, depending on language competence, the context for the conversation and attitudes towards the languages involved.

Being a common practice, we can expect code-switching also among multilinguals with dementia. However, their cognitive decline could potentially lead to more code-switching in general, for instance as a solution to word-finding problems, as well as to instances treated as inappropriate by their conversation partners. This article investigates the functions of code-switching behaviour in seven multilinguals with dementia and discusses to what degree the patterns that emerge may be related to cognitive decline.

\section{Multilingualism, word retrieval and dementia}

Multilinguals have been found to retrieve word slower than monolinguals do (Gollan, Montoya, Fennema-Notestine, \& Morris, 2005). This effect may be explained by the frequency-lag hypothesis: Multilinguals have larger lexicons than monolinguals do, and use each of their words less frequently, making then harder to retrieve (Gollan \& Silverberg, 2001). The delay could also be related to language activation: If all the languages we know are always active (Grosjean, 2008), a multilingual retrieving a given word must suppress not only of semantically and phonologically related words within language (Bybee, 2010), but also competitors from their other languages (Pavlenko, 2009). The suppression or inhibition of competing languages may be connected to cognitive control (Green, 1998; Abutalebi \& Green, 2007): Those who use 
more than one language in their everyday lives tend to score higher on cognitive tasks relying on inhibition (Costa, Hernández, \& Sebastián-Gallés, 2008; Luk, Anderson, Craik, Grady \& Bialystok 2010).

Individuals with dementia undergo cognitive decline, which could lead to problems with language suppression, particularly of an L1 when speaking a language acquired in adulthood (Hyltenstam, 1995). However, they may also use code-switching as a compensatory strategy to bypass problems with lexical retrieval (Hyltenstam \& Stroud, 1993): Since anomia is common within most kinds of dementia, multilinguals with dementia thus have a double disadvantage in this respect.

In conversation, problems with word retrieval are manifested as word-search sequences (Goodwin \& Goodwin 1986), in which a speaker stops and delays the production of a projected word by pausing, producing hesitation markers or sound stretches, and by setting up a 'thinking face' (wrinkled eyebrows, averted gaze). The search activity may thus be presented as a solitary endeavour but could be turned into a collective activity by appealing to the interlocutor for help. The speaker may find the target word, but may also settle for alternatives, such as circumlocutions, approximations and proxies (Svennevig \& Lind 2016). Code-switched words may be considered one such alternative.

\section{Functions of code-switching in conversation}

The functions of code-switching can be either participant-related or discourse-related (Auer 1984). Participant-related switching allows speakers to signal such things as competence in or preference for a certain language or membership in a certain cultural community. Discourse-related switching signals shifts in activity structure, participation framework, or sequential organization of the talk. In our study, we investigate discourse-related alternation by analysing how it is used to address emergent word- 
finding problems in the conversation. We also study participant-related switching by analysing how switching reflects the language skills of the participants and the mental impairments of the PWDs and how they orient to it as appropriate or inappropriate (as observed in the response it engenders).

Code-switching should be distinguished from language mixing, which is a more substantial blending of lexical and morpho-syntactic resources from two or more languages (Muysken 2009). Since the shifts are more frequent and unmarked, they also lose much of their semiotic potential as markers of social identity or discourse organization (Auer 1998).

Depending on the communicative situation, multilinguals may need to inhibit or suppress parts of their linguistic repertoire. For instance, they may communicate with someone who only knows one of their languages or be in a situation where it does not feel natural to communicate in more than one language, or where they will be sanctioned for bringing in other languages. Following Grosjean (1989), we may envision a language mode continuum where the above can be placed at the far monolingual end. At the other and of the continuum, we find communicative situations where speakers share more than one language, and where it feels natural to bring in their shared linguistic competence. One of the practices that are common at this end of the continuum is code-switching.

To place the situation on an appropriate point of the continuum, the communicative partners need to know or make inferences about the interlocutors' linguistic competence, more specifically their active and passive knowledge of various languages. This is a part of a more general process of calculating their common ground (Clark 1996). Speakers continually make assumptions about which words and expressions are common knowledge based on their membership in various cultural 
communities, their so-called communal lexicons (Clark 1998). For multilinguals, then, choosing the appropriate language in a conversation is based not only on inhibition, but also on another aspect of cognitive control, namely the ability to take advantage of contextual cues in the environment, so called facilitation (Luk et al., 2010). With reduced control, the PWD may for instance not realize that the partner does not understand the language used in code-switching or that in a specific setting, for example a monolingual test-situation, only one language is appropriate. Depending on the situation, code-switching in dementia can be treated as either appropriate or inappropriate by the participants in the interaction (Friedland and Miller, 1999).

\section{Previous research on code-switching among multilinguals with dementia}

Previous research on code-switching and language mixing in communication with multilinguals with dementia has taken either a psycholinguistic perspective, focusing on the relation with cognitive decline, or a conversation analytic perspective, focusing on patterns of interaction to manage the challenges faced in such conversations. We will review these two approaches in turn.

Taking a psycholinguistic perspective, Hyltenstam \& Stroud (1985) tested two bilingual patients with dementia who showed problems in the selection and continuation of the appropriate languages in given situations and in keeping languages apart. One of them frequently used code-switching in his conversations. The pattern they observed was that the PWD would frequently switch to his L1 in conversations in his L2, but he would never switch to his L2 in a conversation in his L1. This pattern was more pronounced when the topic of the talk was experiences that he had had before he acquired the L2. The switches also often occurred after prolonged hesitations, indicating that they constituted a solution to a language production problem. The pattern of code- 
switching was related to the PWD's higher proficiency in his L1, as measured by naming tests and utterance length in conversation.

Dronkers, Koss, Friedland \& Wertz (1986) studied an English/Dutch bilingual person with dementia who over time reduced her use of English, her first language, and started using Dutch more and more, even in monolingual English situations. Both languages seemed to be equally affected, so the researchers concluded that her linguistic behaviour was related to memory problems, and not to a differential impairment in the two languages.

De Santi, Obler, Sabo-Abramson \& Goldberger (1990) presented data from four Yiddish/English-speaking women with the diagnosis of probable Alzheimer's Disease (AD), aged between 87 and 96, in discourses with Yiddish and English contexts. For two of the subjects, the two languages seemed differentially affected. Only one subject chose the appropriate language in all situations, while the rest of the subjects made an inappropriate language choice in at least one context. While all subjects were able to code-switch appropriately, two of them also made inappropriate code-switches. The researchers found a correlation with dementia severity: the higher the degree of dementia, the more inappropriate the language choice and code-switching.

The above studies describe problems in dementia both with language choice and with language separation, related to e.g. language proficiency, memory problems and dementia severity. Still, it is often hard to distinguish between the two and assess what the underlying cause is, especially to what extent it is pathological. Inappropriate codeswitching may be caused by other factors than pathological cognitive decline, such as a more accidental or temporary unawareness of the interlocutor's language background.

Researchers in the Conversation Analytic tradition have focused more on whether the code-switching is treated by the participants as appropriate or not, and how 
the interlocutor handles the code-switching behaviour. Friedland \& Miller (1999) studied four women aged 75-89, bilingual in English and Afrikaans and with a probable AD diagnosis. The interlocutors were monolingual speakers of each of the languages, so any code-switching was in principle inappropriate. Results showed code-switching in from 0 to $41 \%$ of the utterances, mainly by inserting words from their L1 in an L2 context. Proficiency in the L2 seemed to be more important for degree of codeswitching than severity of dementia; however, in one speaker code-switching increased when dementia progressed. Detailed analyses showed that not all code-switching led to problems in the conversation. In general, the speakers were not aware of their switching behaviour, and when trouble spots occurred, repair was generally initiated by the interlocutor.

Lindholm (2017) studied bilingual PWDs in a nursing home in Finland for speakers with Swedish as L1 (which is an official minority language in Finland). She observed that short-term residents (spending 2-3 weeks in the care facility) would often initiate talk with others in Finnish. Thereby, they seemed to apply the common strategy used by Swedish-speaking Finns in this bilingual society when approaching someone whose language background they do not know. The long-term residents would frequently reply in Swedish, orienting to that language as the appropriate language of the care facility. The inappropriate language choice of the short-term residents thus seemed to reflect a lack of situational awareness and knowledge of the other residents' language background.

\section{The current study}

The aim of this study is to investigate code-switching among multilinguals with dementia in two different speech contexts: in a test situation of picture naming, and during natural conversation. The setting for both contexts is predominantly 
monolingual, taking place in an L2 (Norwegian) for all participants. However, in the test situation there is a clearer expectation of a monolingual mode, since the pictures should be named essentially with one word in Norwegian. At the same time such naming puts a higher cognitive load on the participant. In conversation data there is a higher acceptance of code-switching - to the languages shared by the interlocutors.

We examine the extent of code-switching, which languages are involved, and its functions and appropriateness. We then discuss to what degree these patterns can be ascribed to properties of their condition. Our research questions are:

(1) Which communicative functions does code-switching fill in multilinguals with dementia in two different settings: confrontation naming in a test situation and language production in more natural conversation?

(2) How appropriate is the code-switching to the situation and the interlocutor's linguistic background?

(3) To what degree are the code-switching patterns related to typical symptoms of cognitive decline associated with dementia?

The typical symptoms of dementia referred to in question 3 are: 1) word retrieval difficulties, 2) episodic memory problems, making it hard to interpret the situation and adapt to the interlocutor, and 3) weakened executive control (especially inhibition), making it difficult to suppress the dominant language in a non-dominant language setting.

\section{Method}

We take an interdisciplinary approach, seeking to combine qualitative and quantitative methods. Test results were quantified in line with traditional psycholinguistic approaches to naming/word retrieval, but the testing situation was also approached qualitatively as an interactional activity, involving various conversational practices and 
strategies for word searching, including code-switching. The qualitative approach used for analysing the interactions is Conversation Analysis. This approach takes the perspective of the participants (an emic approach) and studies how codes are meaningful, functional alternatives to them and how alternating between languages are demonstrably consequential for the interaction (Auer 1998, Mondada 2007). The paper thus integrates psycholinguistic and sociolinguistic methods and theoretical frameworks. The goal of using this interdisciplinary methodology is to study social behaviour in conversation in light of measures of cognitive and linguistic competence and to study the test situation as social interaction between multilingual speakers.

\section{Participants}

We present a multi-case study with seven multilinguals diagnosed with dementia: ‘Sven’ (85 years old, speaking Finland Swedish, Finnish, German, English and Norwegian), 'Koki’ (85, speaking Japanese, English and Norwegian), 'Gabriel' (67, speaking English, an African Creole language and Norwegian), 'Ali' (77, speaking Urdu, English and Norwegian), 'Rey’ (73, speaking Tamil, English and Norwegian), 'Laura' (73, speaking English, French and Norwegian) and 'JJ' (69, speaking English and Norwegian). ${ }^{1}$ All participants lived at home at the time of data collection, which was done in their home, at the university or in a day care center.

All seven participants had acquired Norwegian as a second language in their late teens or twenties. Two of them, JJ and Laura, grew up as monolingual speakers of English, whereas the rest acquired multiple languages from birth (Sven, Koki and

\footnotetext{
${ }^{1}$ Languages are listed in order of acquisition, and by dominance if two languages were acquired simultaneously. JJ has been presented as a case in two previous papers, Svennevig \& Lind (2016) and (Lind et al., 2018).
} 
Gabriel) or early school years (Ali and Rey). According to self-reports, the dominant language was Japanese for Koki, Tamil for Rey and English for Gabriel, Laura and JJ. Ali responded that his strongest language was Norwegian, his last acquired language.

\section{Biographical interviews and conversational data}

The participants were interviewed about their language background and their linguistic practices over the lifespan. In addition, we collected naturally occurring interaction in an everyday speech context, without a researcher present. The interviews and conversations were transcribed in accordance with CA conventions (see Appendix).

We analysed the code-switching patterns in the biographical interviews and in four recordings of informal conversation between care providers (nurses in institutional or home help service) and some of the participants (Gabriel, Koki, Sven and Rey). We limit the data analysed here to interactions in Norwegian. The first reason for this is that this is a common L2 to all the participants, thereby facilitating comparison between them. Second, Norwegian is the language of their everyday contact with health care providers, thereby being an important language for the management of their daily affairs. Since Swedish and Norwegian are closely related and mutually intelligible, and most adults in Norway know English, we expect these languages to be less suppressed than other languages in our participants' repertoire.

\section{Cognitive assessment}

The participants went through a battery of cognitive tests. Here, we will analyse data from two of the tools included in this battery, namely the Rowland Universal Dementia Assessment Scale (RUDAS) (Storey, Rowland, Conforti, \& Dickson, 2004) and the Flanker test (Eriksen \& Eriksen, 1974). 
RUDAS is a general cognitive screening tool, very similar to the more widely used Mini-Mental State Examination (MMSE; Folstein, Folstein, \& McHugh, 1975), but it has been found to be less sensitive to education level and language background (Nielsen et al., 2018; Rowland, Basic, Storey, \& Conforti, 2006). It is thus more suitable for our participants. The tool covers the following domains: memory, spatial orientation, praxis, visuo-constructional drawing, judgment, and language. It has a maximum score of 30, with a cut-off point of 23 for neurologically healthy individuals. As can be seen in table 1, Rey, Ali and Laura all scored at this point, whereas Gabriel, Sven, Koki and JJ scored below. Note that for Sven, his low score can be partly accounted for by motoric problems.

Table 1. RUDAS and Flanker results from the seven participants

\begin{tabular}{lccccccc}
\hline & Gabriel & Sven & Koki & JJ & Ali & Rey & Laura \\
& & & & & & & \\
\hline RUDAS & 14 & 16 & 22 & 22 & 23 & 23 & 23 \\
Flanker (SCE) & 0,07 & NA & 0,04 & 0,14 & 0,22 & 0,37 & 1,03 \\
\hline
\end{tabular}

The Flanker test was included to measure the participants' executive functioning more directly. In this test, participants are shown five arrows on a screen. There are two conditions: The congruent condition, where all arrows point in the same direction, and the incongruent condition, where the middle arrow points to one direction, and the other four in the other way. The participant should press a button according to the direction of the mid arrow, disregarding the other four. It is assumed that a correct answer in the incongruent condition requires inhibition, and more so after a congruent trial than after another incongruent trial. A measure that reflects the relative cost of shifting between congruent and incongruent trials is the sequential congruency effect (SCE) (Grundy et al. 2017). 
Our participants were tested on 40 sequences in randomised order, half in the congruent condition and half in the incongruent condition. The stimuli were presented on a 13' laptop, and accuracy and reaction time were measured with ePrime and a response box. SCE scores (calculated from the participants' correct answers only) are given in table 1. Sven gave too many wrong answers for calculation. Of the others, the extra cost of switching between conditions was highest for Laura and lowest for Koki and Gabriel, with JJ, Rey and Ali in between. If there is a connection between this inhibition cost and the ability to suppress an inappropriate language, we would expect more inadvertent code-switching and/or language mixing from Laura and Sven than the others.

\section{Lexical assessment}

The battery of language assessment tools consisted of several tools, including a naming task with 31 drawings depicting objects taken from the Norwegian versions of Psycholinguistic Assessments of Language Processing in Aphasia (PALPA) (Bastiaanse, Lind, Moen, \& Simonsen, 2006; Kay, Lesser, \& Coltheart, 1996), and 31 drawings depicting actions taken from the Verb-and Sentence Test (VAST) (Bastiaanse, Edwards, Mass, \& Rispens, 2003). The participants completed the naming tasks in all languages in active use, with at least a week between each language, and different administrators for each language. Attempts were made to establish a monolingual setting. The test administrator only used the target language, keeping feedback at a minimum. If the participant named several items in a row in a non-target language, a prompt was given to answer in the target language.

The participants were instructed to name each object and action with one word if possible, but often gave longer answers. We transcribed the whole response, scoring them based on whether the target word was included in the response. In addition, we 
registered code-switching in their full responses by language. The transcription and scoring were performed by the second author. Code-switching to Swedish or French was checked with the first and third author, and any speech from Koki noted as possibly Japanese was checked, transcribed and translated by a Japanese speaker.

\section{Ethical considerations}

The participants were recruited through a hospital memory clinic, home nursing care services and nursing homes. The study was approved by the Norwegian Centre for Research Data, the Regional Committee for Medical and Health Research Ethics, and the data protection officer at the hospital and endorsed by the municipality's head of health services. Prior to data collection, participants and interlocutors received oral and written information about the study and signed a written consent. To ensure that participation was informed and voluntary, we repeated the information orally to the participants and obtained their oral consent before every subsequent data collection session.

\section{Results and analyses}

\section{Lexical assessment}

In this section we analyse the results from the naming tasks, both quantitatively and qualitatively, beginning with the test scores summarised in table 2. Rey and Koki score highest, responding correctly on about half of the 62 items, with Ali, Gabriel and Sven right behind. At the lower end, we find Laura, with only 9 correct responses, and JJ, with 20. Although instructed to answer in Norwegian, all participants code-switched to English during the task. The participant with the highest amount of English in his responses, was JJ. When he failed to name items or named them in English, he often made metacommunicative comments on his own retrieval process, typically in English, 
with phrases like 'I mean I know exactly what it is'. When the other participants named objects or actions in English, this was seldom marked in any way.

Whereas Rey, Ali and Gabriel refrained from using any other languages, Sven, Koki and Laura involved one other language as well. Sven appeared to mix Norwegian and Swedish. Since the languages are closely related, it is hard to tell which language he is using for many of the responses. However, he gave at least 36 responses involving Swedish words, without signaling inappropriateness. Several of these lack Norwegian cognates and are not readily understood by Norwegians.

Table 2. Number of correct Norwegian responses in the Norwegian naming task $(n=62)$, correct responses in other languages, and the number of responses that involved code-switching to English or another language. For Laura, the other language involved was French, for Koki it was Japanese, and for Sven it was Finland Swedish.

\begin{tabular}{llllllll}
\hline & Gabriel & Sven & Koki & JJ & Ali & Rey & Laura \\
\hline Correct (Norwegian) & 27 & 26 & 31 & 20 & 29 & 33 & 9 \\
Code-switching to & 7 & 1 & 14 & 22 & 12 & 9 & 9 \\
English & & & & & & & \\
Code-switching to & 0 & $36+$ & 3 & N/A & 0 & 0 & 1 \\
another language & & & & & & & \\
\hline
\end{tabular}

Laura, who had severe difficulties with word retrieval and mostly answered through iconic gestures, gave one response involving French: Han er musicien ' $\mathrm{He}$ is (a) musician'. She did not comment on neither this French word nor any of her nine code-switches into English, nor mark them as inappropriate in any way.

Koki involved Japanese in three of his responses. In two cases, he whispered the Japanese phrase, apparently to himself to help evoke the Norwegian word. In the last 
case, he first explicitly expressed that he did not remember the word, before giving the Japanese word as a proof of his recognition of the concept (see excerpt 1):

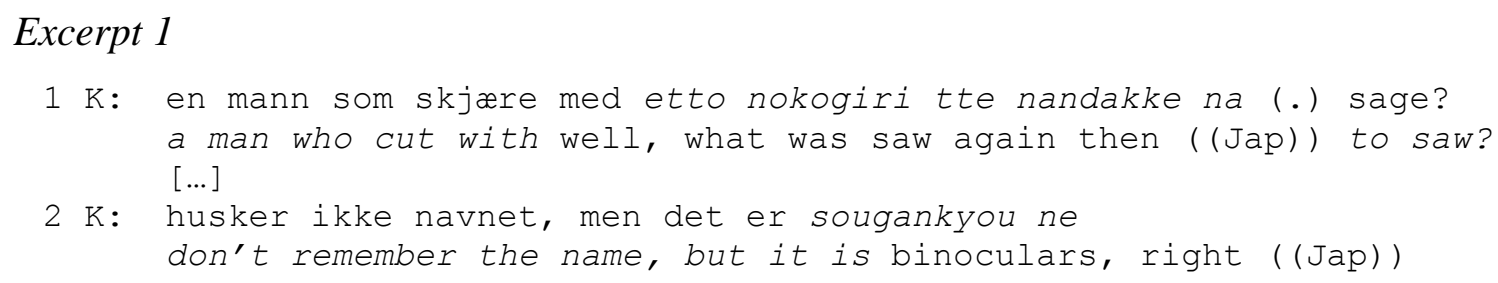

To sum up, code-switching is used with three different functions in the test situation with confrontation naming in Norwegian. First, the response may be given in another language without the participant's commenting on it in any way - this is most prominent in Sven's use of Swedish but found to larger or lesser degrees in all participants. Second, the response may be given in another language but clearly marked as such, either to show that the PWD knows the concept but not the word in Norwegian, or as a prompt to find the correct word in Norwegian, as exemplified with Koki's use of Japanese, but also used by JJ. Third, another language may be used as a metacomment to the actual response, found to a large degree in JJ's, but also in Koki's responses.

\section{Conversational data}

In this section we analyse the conversational data with a focus on the communicative functions served by code-switching and how the participants orient to it as more or less appropriate in the situation.

\section{Word search function}

In the conversational data, a common function of code-switching is substituting a word in the L2 that seems to be inaccessible to the speaker. This can be observed in that the code-switching occurs as a solution to a word search or as a self-repair after the production of an incorrect word. We illustrate the latter case first, in excerpt (2) below, 
from a biographical interview. The PWD Laura (L) is telling the researcher $(\mathrm{P})$ about her childhood and runs into trouble naming the profession of her father:

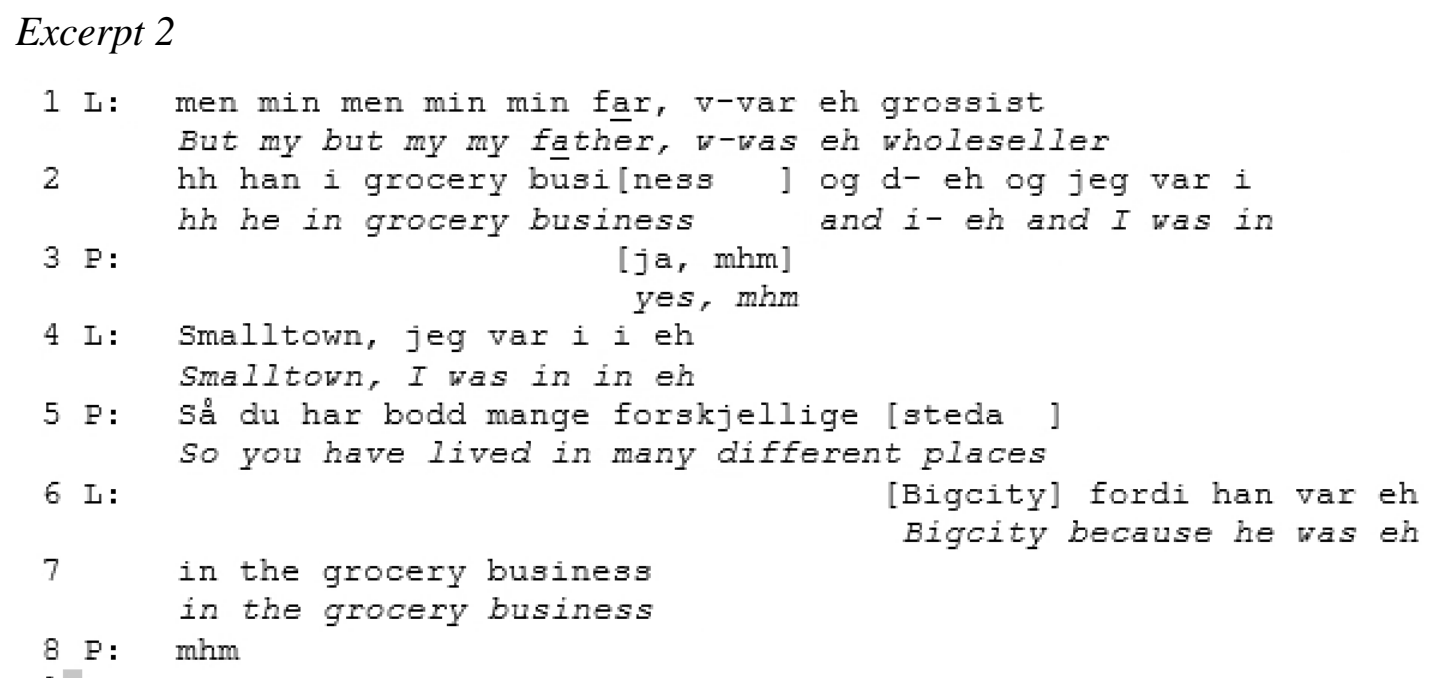

In line 1, after a slight hesitation marker ('eh'), Laura produces a potentially appropriate referring expression in Norwegian, grossist. She then self-repairs by substituting it with a paraphrase in English, namely that he was in the grocery business. The word grossist is a distant cognate of 'grocery' but constitutes a so-called 'false friend' in that it means 'wholesaler' and not 'grocery store employee (or owner)' (which in Norwegian is a non-related word, dagligvarehandler). The participants treat the codeswitching as unproblematic. The interlocutor (P) explicitly claims understanding of this code-switched self-repair by producing a continuer in line 3, and Laura continues her account (in Norwegian), thus treating the act of reference as successful. The codeswitching here thus constitutes a repair solution to a word selection problem and displays an inability to access the appropriate lexical item in Norwegian. This is further evidenced by the fact that she switches back to English also the next time she refers to his profession (line 7).

That code-switching is used as a resource for avoiding a lexical retrieval problem in the L2 is also evident in word search sequences. In excerpt (3), the PWD 
Koki $(\mathrm{K})$ is talking with a home care nurse Amina (A) about a tube of dental adhesive, which is now empty.

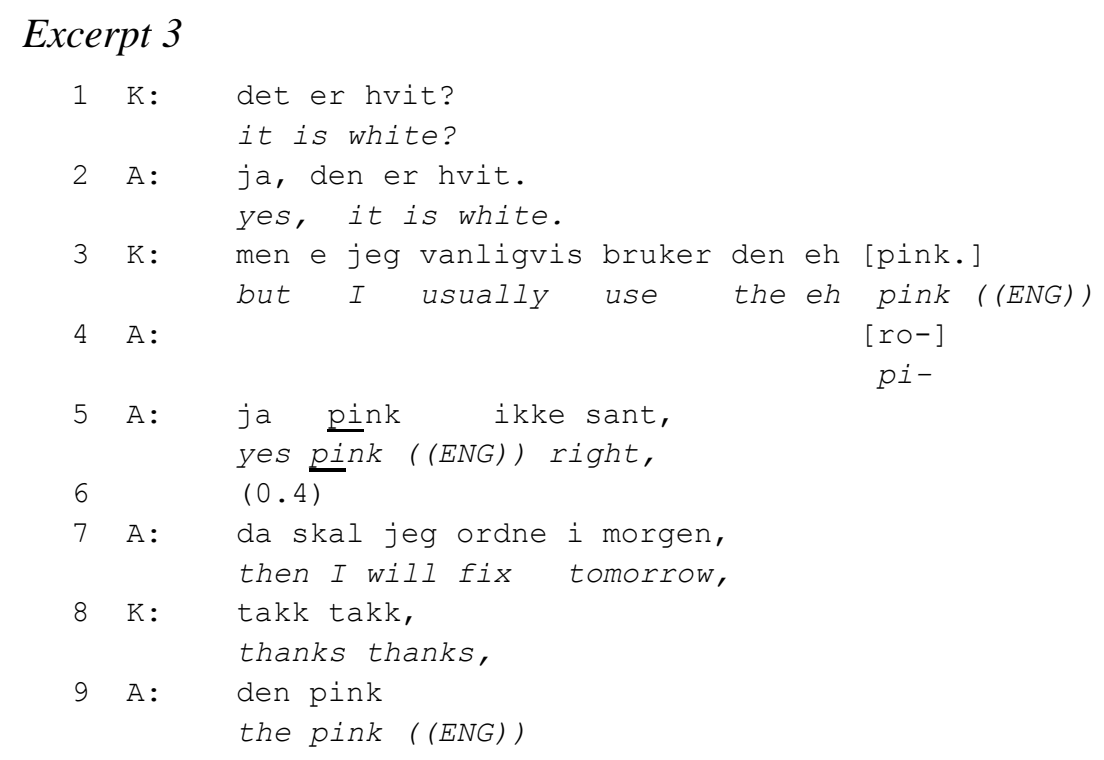

In line 3, Koki switches to English when describing the color of the tube he usually uses, saying pink instead of rosa. The code-switched adjective comes after a slight hesitation marker ('eh'), which the nurse treats as indexing a word finding problem in that she enters his turn space with a candidate suggestion, most probably the Norwegian word for pink, 'rosa', in line 4. However, this collaborative completion is aborted mid-course as Koki simultaneously completes the utterance himself. The nurse subsequently produces a receipt of information, repeating the code-switched word used by Koki rather than the Norwegian word she was about to produce herself (line 5). Also the next time she refers to the colour, in an utterance more independently formulated by her, does she use the English adjective (line 9). She thus adopts his choice of term and thereby displays acceptance of his code-switching.

In other cases, code-switched lexical items do not appear as a solution to a word retrieval problem. In the next excerpt, the PWD Ali is talking about a family member, who died when he was young:

Excerpt 4 


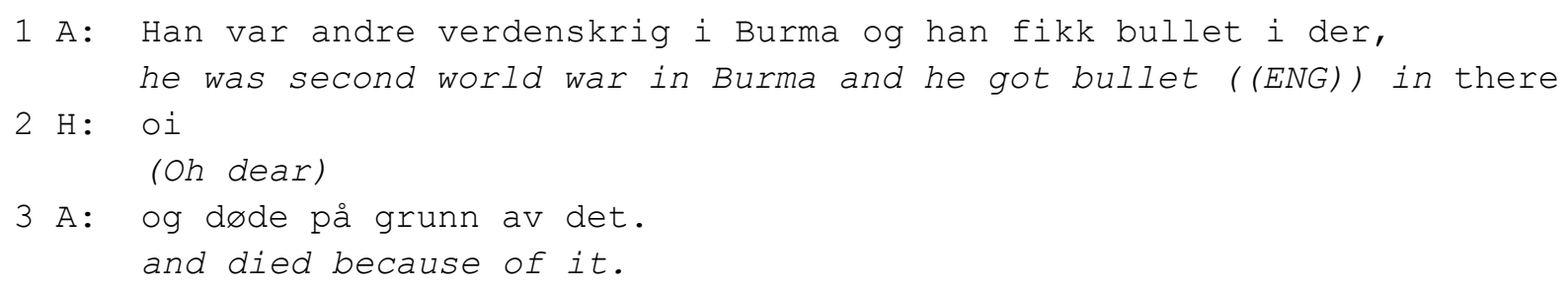

The code-switched noun bullet does not come after any hesitation or other indications of word finding problems. However, it does not create any problem either, as the interlocutor responds with a marker of astonishment, thus treating the report as understandable. One potential explanation of the code-switching is that it is due to a lack of knowledge of the lexical item or a retrieval problem, given that the word in question is somewhat low-frequent and does not constitute a cognate (the Norwegian word is 'kule'). However, there are no manifest signs of searching, so the switch may also be caused by a lack of inhibition of the dominant language, English.

In sum, code-switching often serves as a solution to a word retrieval problem, as manifested in patterns of self-repair and word search. It thereby has a participant-related function in displaying the speaker's greater proficiency in the language switched to (at least concerning the lexical item in question). There are also some switches that do not come in connection with self-repair or word searching, and these are potentially related to a lack of inhibition and thus to cognitive decline.

\section{Marking metacommunicative parentheses}

In some cases, code-switching occurs in utterances that may be considered parentheses or asides in relation to the main activity (Mazeland 2007). Some of them are metacommunicative expressions of frustration about problems of speech production. In the data, it is especially Laura (L) who has many instances of this, as exemplified here in an extract from a biographical interview with a researcher $(\mathrm{P})$. 


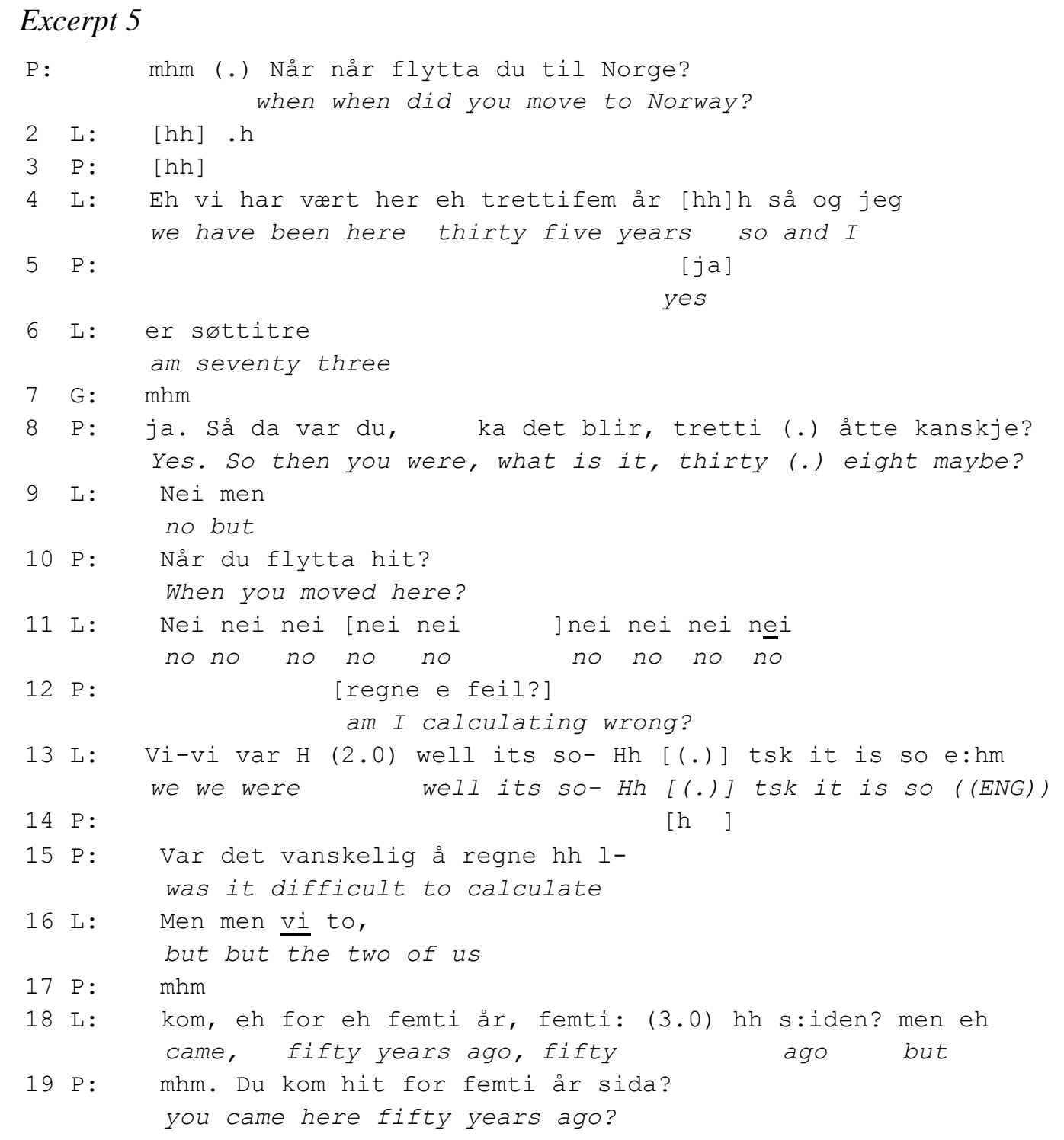

We can see here that the code-switching in line 13 comes at a point where Laura has had severe problems answering P's original question and her subsequent prompts (lines $8,10,12$ ). Her frustration at not being able to answer may be gleaned in the emphatic and extensive repetition of negative polarity tokens in line 11. In line 13 she thus seems to make a fresh start by producing what seems to be a new answer to the original question. However, the sentence is aborted, after some hesitation and pausing, and the code-switched part inserts the beginning of a new syntactic structure (it's so). This utterance seems to initiate a metacommunicative parenthesis, expressing her 
frustration with not being able to continue the utterance, at least this is how it is interpreted by $\mathrm{P}$ in her understanding check (line 15). In addition, it provides an account for her inability to provide an answer, treating the problem as exceptional (Svennevig \& Landmark 2019). The code-switching thus has a discourse-related function, in marking parts of the talk as being distinct from and inserted into the main activity of the talk.

In the next excerpt, Laura is asked whether she has used French actively as an adult. After some insertion sequences and some hesitation, she produces what is hearable as an answer to the question:

\section{Excerpt 6}

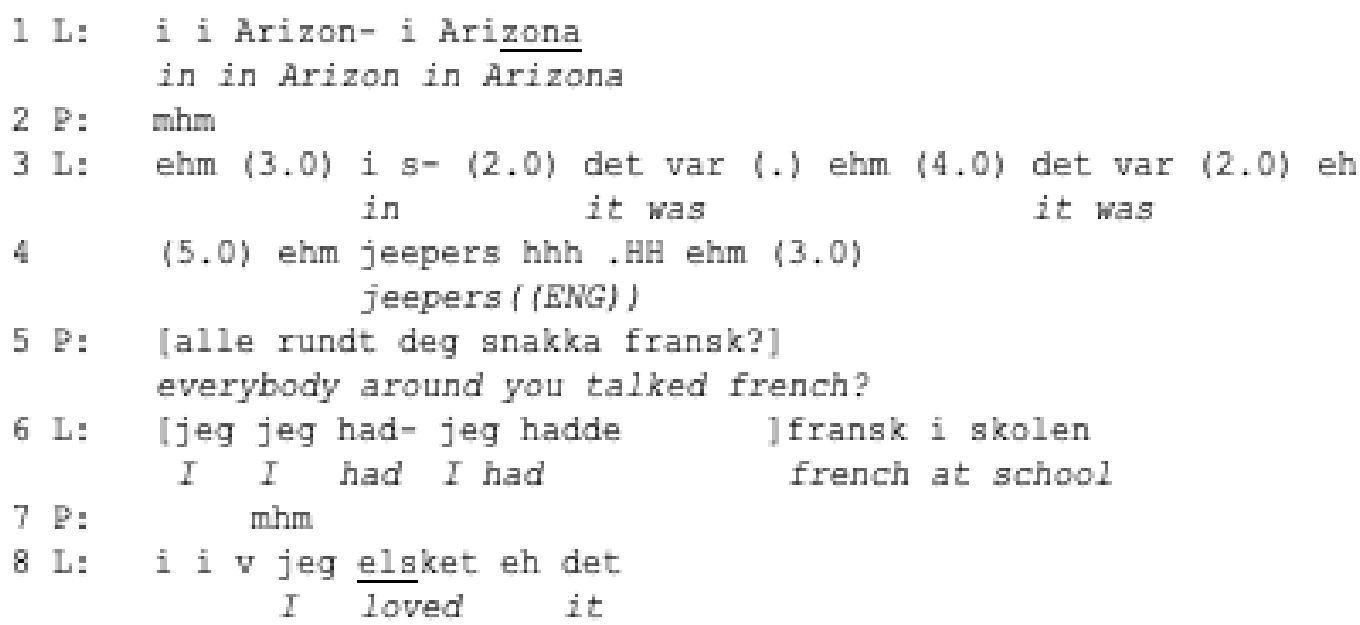

After having provided an initial constituent, Laura runs into severe problems continuing the utterance. After a restart, several hesitation markers and prolonged pauses, she produces the English swear word jeepers (line 4). After yet some more hesitation, she produces what seems to be a continuation of the utterance, in Norwegian. The swear word thus constitutes a metacommunicative aside in relation to the ongoing production of an utterance in Norwegian. Swear words may have both an expressive function, 'letting out steam' in situations of frustration, but may also have a function of informing interlocutors about this frustration, thereby accounting for their production problems (Robinson 2016). 
Another form of discourse-related code-switching is found when speakers are talking to themselves, for instance 'thinking aloud'. In the next excerpt, Koki has been asked whether he has any siblings. After reporting that he had a sister that was five years older than him, he proceeds to the other sibling.

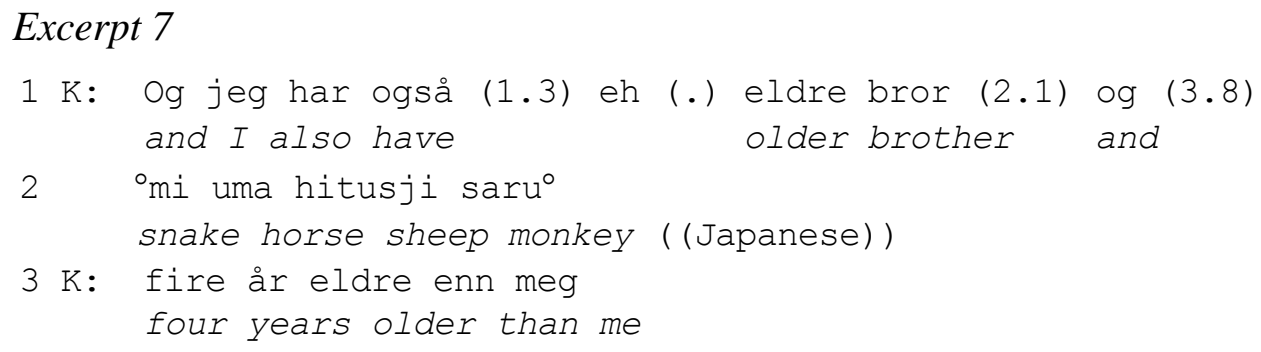

Before providing the age of the brother, Koki switches to Japanese and calculates the age with low voice and averted gaze. The code-switching thus serves the discursive function of marking a section of the turn as an aside, a self-addressed insertion into the ongoing turn. The interlocutor orients to this as soliloquy by not initiating repair or otherwise intervening, even though the talk is most probably not comprehensible to her.

In sum, several instances of code-switching have a discourse-related function in marking a section of talk as a metacommunicative parenthesis in relation to the main business of the talk. This may also have a participant-related function in displaying the preferred language for expressing emotions or cognitive processing but does not seem to relate to problems of inhibition or cognitive control. It may further be compared to the metacommunicative insertions in the naming test, where participants (especially JJ) would also comment on their processing problems in English.

\section{Inappropriate code-switching}

In a few cases code-switched words are treated as less appropriate or understandable by the interlocutor. We can see this in the next excerpt (8), where Sven (S) makes a remark to his home help nurse $(\mathrm{N})$ about his success in catching a ball: 


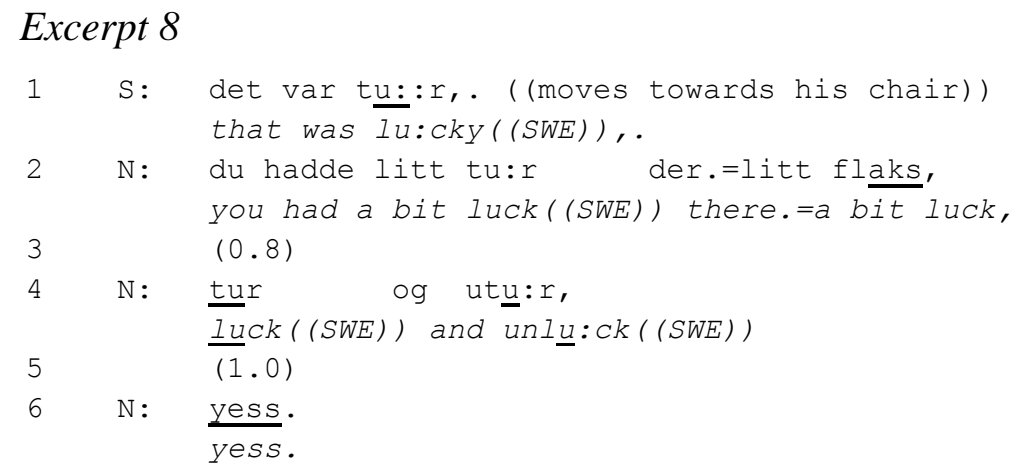

Sven code-switches to Swedish in saying tur (luck) (line 1). The nurse claims understanding by repeating his utterance in a slightly modified form. However, in the process of rephrasing it she does not change the code-switched word. Only subsequently does she self-repair, replacing it with the Norwegian equivalent flaks. She thereby partly accepts his code-switching, but also displays an orientation to it as not fully appropriate by correcting it. The delicacy of this other-correction may be what triggers her subsequent metalinguistic quoting of an idiom, tur og utur ('luck and unluck'), displaying her familiarity with the Swedish word.

Sometimes code-switching even creates problems of understanding. In the next excerpt (9), Sven uses a Swedish low-frequency word for 'inn-keeper' (krøgare), which is quite different from that Norwegian counterpart (krovert), and this leads to a repair sequence:

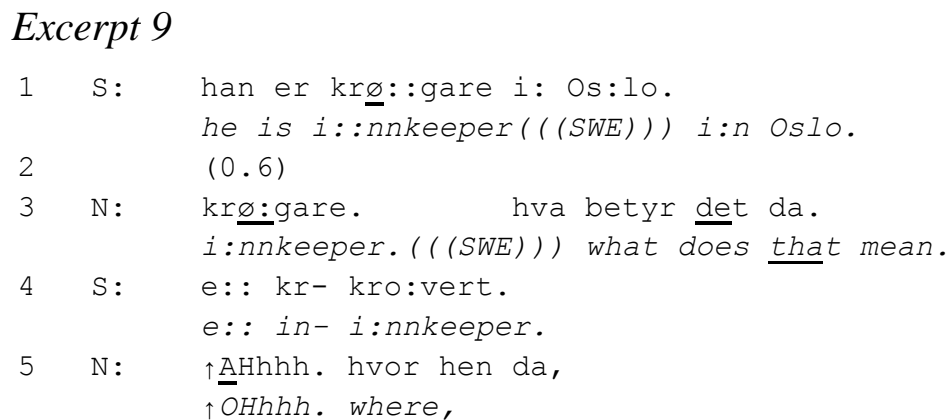

The code-switched word is straight-forwardly produced without any signs of hesitation or word-searching. The nurse repeats the trouble source word and adds an explicit indication of an understanding problem: 'What does that mean?'. In response, 
Sven provides a Norwegian word, which the nurse treats as new information by producing a change-of-state token ('AHhhh') (line 4). So here, the code-switching is treated as inappropriate, or problematic, in that he uses a Swedish word that is unknown to the nurse. The word is rather low-frequent, and despite somewhat related, not transparent as a cognate. The switching may thus be related to either a lack of inhibition or to a lack of situational awareness.

There is also an instance where a PWD switches to his L1 (English) for a longer stretch of talk, even though the interlocutors continue in Norwegian. The excerpt (10) is from a biographical interview with JJ, conducted by two researchers (I and II):

\section{Excerpt 10}

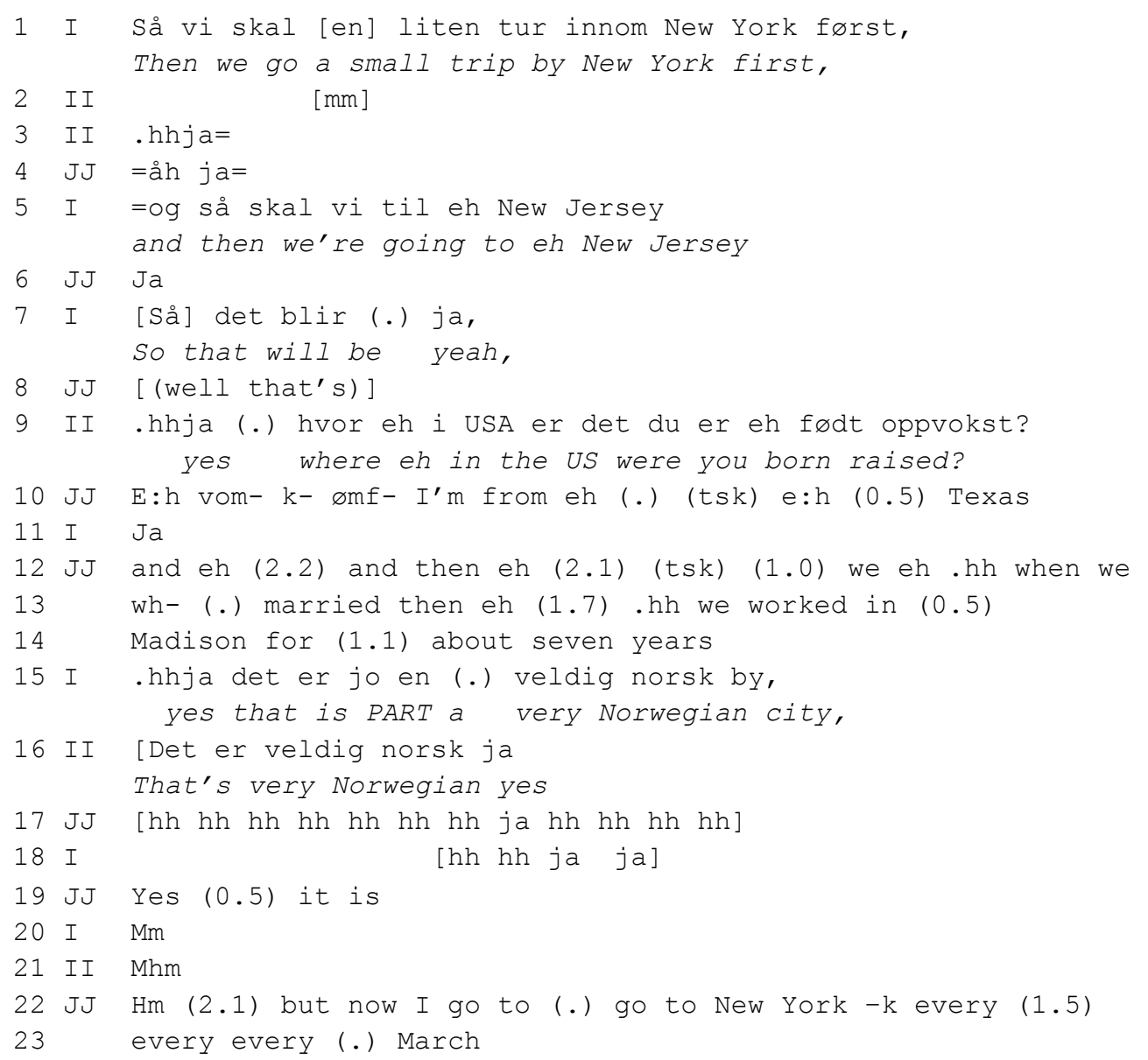

Here, JJ switches to English already in line 8, responding to the interviewers' report about going to cities in the US (for a conference). And when they resume the 
interview, asking him a new question, he responds in English (line 10). The interlocutors claim and display understanding of what he says but mark the choice of code as inappropriate by returning to Norwegian (line 15-16). In this interview, the researchers had a pronounced aim of constructing a monolingual mode of talk, and thus their resistance towards switching to English must be considered a conscious strategy. Apart from a single acknowledgement token in Norwegian (line 17), JJ continues in English, both when confirming their claim (line 19) and when resuming the account of his relationship to the US (line 22). This pattern continues for another couple of rounds of him telling about trips to the US and the interviewers responding in Norwegian (data not shown). Only when one of the interviewers produces a more substantial turn, does he switch back to Norwegian. By adjusting to their language choice, he implicitly acknowledges and accepts their treatment of his code-switching as inappropriate. The code-switching here does not seem to serve any specific purpose of discourse organization or identity construction, but rather seems to be an unmotivated switch triggered by the topic of the conversation, and thus potentially constitutes a case of lack of inhibition of the L1.

In sum, there are some instances of code-switching that are treated as more or less inappropriate or problematic by the interlocutors. They all constitute switches to the speakers' more dominant language and occur without any signs of word searching activity. Instead they are repaired or corrected in subsequent turns. As such, they are treated as inappropriate lapses into a different language, and thereby one might speculate whether they result from lack of inhibition rather than a communicative strategy. 


\section{Discussion}

In this study, we used two different approaches to study the communicative functions of code-switching in multilinguals with dementia, the appropriateness if their codeswitching behaviour and the relation between this behaviour and cognitive functioning. We applied both cognitive and psycholinguistic tests from a quantitative perspective and a more qualitative approach, Conversation Analysis. This cross-disciplinary methodology has allowed us on the one hand to interpret social behaviour (codeswitching) considering cognitive and linguistic skills, and on the other, to understand test scores (and thereby linguistic skills) as a result of social interaction in the test situation. Our claim is that this combination of approaches gives a more nuanced picture of both L2 proficiency and code-switching patterns. The current study thus constitutes a plea for crossing traditional boundaries in research on language and dementia.

In relation to our first research question, two main communicative functions of code-switching were identified in the tests and conversations. One is substituting lowfrequency content words in the L2 (Norwegian) by equivalents in another language. This function may be considered as related to the dementia condition in that it constitutes a resource allowing the PWDs to compensate for word retrieval problems (the first category of typical dementia-related problems listed above). Even in a predominantly monolingual context, the speakers manage to convey their meaning despite the lexical gap. In naming tests, they manage to display recognition of the concept involved (even if they cannot find the correct word) and in conversations, they make themselves understood without interrupting or delaying the progressivity of the talk unnecessarily. In most cases, we interpret these instances of code-switching as a strategic choice rather than a result of lacking inhibition (the third category of dementia symptoms). This is because the speakers consistently switch to a language that they have reason to believe that the interlocutor will know (English or Swedish). Only in one 
case does the PWD use a word from a language that is not known to the interlocutor (musicien, French).

The second main function of code-switching is producing metacommunicative asides related to the process of speech production, such as expressions of frustration or self-addressed memory prompts. This may also be considered a communicative resource related to word retrieval problems (and thus dementia). When the progressivity of the talk is threatened by protracted pauses and hesitations, speakers will generally be expected to account for the causes of the delay (Robinson 2016). The metacommunicative insertions provide such accounts by displaying to the interlocutor that the speaker is engaged in the activity of word searching and committed to pursuing the endeavour further.

Regarding our second research question, most instances of code-switching are treated by the interlocutors as appropriate in that they claim understanding and continue the communicative activity at hand rather than initiating repair or producing corrections. In combination with the fact that the PWDs generally switch to a language known by the interlocutor, this provides evidence that code-switching in these data is generally not related to problems of assessing the situation and adapting to the linguistic background of the speakers (and thereby to problems of episodic memory).

Concerning our last research question, a small residue of instances may be interpreted as resulting from cognitive decline. These are the instances where the PWDs switch to a language that is not known to the interlocutor (musicien) or produce a longer stretch of discourse in a different language than the established code of the interaction (excerpt (10)). Interestingly, the participants who produce these code-switches (Laura and JJ) are the ones with the lowest scores on the test measuring inhibition (Flanker). 
They also score far lower on the naming task than the other participants, indicating substantial word-finding problems.

Some code-switches are potentially related to a lack of suppression of a nontarget language. The participants code-switch substantially more in the naming tests than in the interviews and everyday conversations, despite the instruction to name objects in Norwegian. This may be a result of the fact that the cognitive effort involved in this task is substantially higher. The general cognitive load may thus have a negative effect on inhibition, leading to more code-switching.

As noted above in the discussion of previous studies, it is difficult to ascertain the causes of inappropriate code-switching and attributing it to pathological cognitive decline. We therefore restrict ourselves to claiming that these instances are possibly, but not necessarily, related to the dementia condition.

Both in tests and conversations there are also several instances of code-switched words that do not occur as a solution to a word-search, particularly from Sven (such as in excerpts 8 and 9). These may potentially be related to a lack of inhibition, as they do not seem to fill any other discernible discourse-related function. However, also neurotypical multilinguals occasionally code-switch without any obvious discourseorganizational or rhetorical function (Auer 1998). Thus, interpreting these instances as 'pathological' would presuppose monolingual speech as the norm, and this is clearly not the case in interaction between multilinguals.

Most previous studies (reviewed above) have focused on 'pathological' codeswitching, involving inappropriate use of L1 in L2 contexts. This study contrasts with these studies by showing that code-switching in these data is seldom a problem, on the contrary, that it constitutes a resource for overcoming word-finding problems in an L2. 
The PWDs also generally show a high degree of situational awareness by switching to a language known to their interlocutor rather than to their L1.

We see three possible reasons for these contrasting findings. The first relates to differences in language competences, practices and policies in the societies studied. The Norwegian society has a 'monolingual' identity and to a large extent monolingual language practices are the norm, but at the individual level, hardly anyone is a monolingual: Everyone knows English and most use it in their everyday lives (Rindal, 2013). Furthermore, the mutual intelligibility of the Scandinavian languages means that the use of Swedish in a Norwegian setting is usually seen as unproblematic. Such (socio-)linguistic conditions must be considered when comparing findings across studies.

Secondly, there may be differences in severity of the dementia condition in the participants. However, most studies do not provide information about the participants' cognitive state and consequently it is not possible to compare. This limitation thus shows the need for studies that combine cognitive and interactional approaches, such as the current one.

The third possible reason for contrasting findings is a difference in theoretical perspective, especially whether one focuses on the problematic instances of codeswitching or the successful ones. The first kind of focus involves a deficit perspective on multilingualism, while the latter conforms to a resource perspective (Ruiz 2010). The current study presents results of both kinds and thus seeks to redress the problemfocused, pathological bias that has dominated the field up until now.

This study thus adds to the knowledge base on code-switching in dementia by emphasizing its functions as a remedy for anomia, a typical dementia-related problem, rather than a symptom of lacking inhibition or reduced cognitive control. 


\section{Conclusion}

Through a multi-method approach, this study finds code-switching to be primarily a resource for PWDs in overcoming word-finding problems in an L2, both in naming tests and in informal conversation. Most instances are appropriate in the situation and display competence in evaluating the language background of the interlocutors. Only a small residue may be interpreted as resulting from cognitive decline.

\section{References}

Abutalebi, J., \& Green, D. (2007). Bilingual language production: The neurocognition of language representation and control. Journal of neurolinguistics, 20(3), 242275.

Auer, P. (1984). Bilingual conversation. Amsterdam: Benjamins.

Auer, P. (1998). Introduction: Bilingual conversation revisited. In P. Auer (ed.), Codeswitching in conversation, 9-32. London: Routledge.

Bastiaanse, R., Edwards, S., Mass, E., \& Rispens, J. (2003). Assessing comprehension and production of verbs and sentences: The Verb and Sentence Test (VAST). Aphasiology, 17(1), 49-73.

Bastiaanse, R., Lind, M., Moen, I., \& Simonsen, H. G. (2006). Verb- og setningstesten (VOST). [The verb and sentence test]. Oslo: Novus forlag.

Bybee, J. (2010). Language, usage and cognition (Vol. 98): Cambridge University Press Cambridge

Clark, H.H. (1996). Using language. Cambridge: Cambridge University Press.

Clark, H.H. (1998). Communal lexicons. In Kirsten Malmkjaer \& John Williams (eds), Context in language learning and language understanding, 63-87. Cambridge: Cambridge University Press. 
Costa, A., Hernández, M., \& Sebastián-Gallés, N. (2008). Bilingualism aids conflict resolution: Evidence from the ANT task. Cognition, 106(1), 59-86.

Eriksen, B. A. \& Eriksen, C. W. (1974). Effects of noise letters upon identification of a target letter in a non-search task. Perception and psychophysics, 16, 143-149.

Goodwin, M. H. \& Goodwin, C. (1986). Gesture and coparticipation in the activity of searching for a word. Semiotica, 62, 51-76.

Gollan, T. H., Montoya, R. I., Fennema-Notestine, C., \& Morris, S. K. (2005). Bilingualism affects picture naming but not picture classification. Memory \& cognition, 33(7), 1220-1234.

Gollan, T. H., \& Silverberg, N. B. (2001). Tip-of-the-tongue states in Hebrew-English bilinguals. Bilingualism: language and cognition, 4(1), 63-83.

Green, D. W. (1998). Mental control of the bilingual lexico-semantic system. Bilingualism: Language and Cognition, 1, 67-81.

Grosjean, F. (1989). Neurolinguists, beware! The bilingual is not two monolinguals in one person. Brain and Language, 36(1), 3-15.

Grosjean, F. (2008). Studying bilinguals. New York, NY: Oxford University Press, USA.

Hyltenstam (1995). The code-switching behaviour of adults with language disorders with special reference to aphasia and dementia. In: Milroy, L., \& Muysken, P. (Eds.). One speaker, two languages: Cross-disciplinary perspectives on codeswitching. Cambridge University Press, p. p. 302-343.

Hyltenstam, K., \& Stroud, C. (1993). Second language regression in Alzheimer's dementia. Progression and regression in language, 222-242.

Kay, J., Lesser, R., \& Coltheart, M. (1996). Psycholinguistic assessments of language processing in aphasia (PALPA): An introduction. Aphasiology, 10(2), 159-180. 
Lind, M., Simonsen, H. G., Ribu, I. S. B., Svendsen, B. A., Svennevig, J., \& de Bot, K. (2018). Lexical access in a bilingual speaker with dementia: Changes over time. Clinical Linguistics \& Phonetics, 32(4), 353-377.

Li Wei (2002). 'What do you want me to say?' On the Conversation Analysis approach to bilingual interaction. Language in Society, 31, 159-180.

Lindholm, C. (2017). Ageing as a Swedish-speaking Finn: Positioning and language choice at a nursing home. In C. Plejert, C. Lindholm \& R. W. Schrauf (eds.), Mutlingual interaction and dementia, 23-51. Bristol: Multilingual Matters.

Luk, G., Anderson, J. A., Craik, F. I., Grady, C., \& Bialystok, E. (2010). Distinct neural correlates for two types of inhibition in bilinguals: Response inhibition versus interference suppression. Brain and cognition, 74(3), 347-357.

Mazeland, Harrie (2007). Parenthetical sequences. Journal of Pragmatics, 39, 1816-69. Mondada, L. (2007). Bilingualism and the analysis of talk at work: Code-switching as a resource for the organization of action and interaction. In M. Heller (ed.), Bilingualism: A social approach, 297-318. Basingstoke: Palgrave Macmillan.

Muysken, P. (2009). Mixed codes. In P. Auer \& Li Wei (eds.), Handbook of multilingualism and multilingual communication. Berlin: Mouton de Gruyter.

Nielsen, T. R., Segers, K., Vanderaspoilden, V., Bekkhus-Wetterberg, P., Bjørkløf, G. H., Beinhoff, U., . . Gkioka, M. (2018). Validation of the Rowland Universal Dementia Assessment Scale (RUDAS) in a multicultural sample across five Western European countries: diagnostic accuracy and normative data. International Psychogeriatrics, 1-10.

Pavlenko, A. (2009). Conceptual representation in the bilingual lexicon and second language vocabulary learning. The bilingual mental lexicon: Interdisciplinary approaches, 125-160. 
Rindal, U. E. (2013). Meaning in English: L2 attitudes, choices and pronunciation in Norway. PhD thesis, University of Oslo, Oslo. http://urn.nb.no/URN:NBN:no67682

Robinson, J. D. (2016). Accountability in social interaction. In J. D. Robinson (ed.), Accountability in social interaction, 1-46. Oxford: Oxford University Press.

Rowland, J. T., Basic, D., Storey, J. E., \& Conforti, D. A. (2006). The Rowland Universal Dementia Assessment Scale (RUDAS) and the Folstein MMSE in a multicultural cohort of elderly persons. International Psychogeriatrics, 18(1), 111-120.

Ruiz, R. (2010). Reorienting language-as-resource. In Petrovic, J. (ed.), International perspectives on bilingual education. Policy, practice and controversy, 155-172. Charlotte, NC: Information Age Publishing.

Storey, J. E., Rowland, J. T., Conforti, D. A., \& Dickson, H. G. (2004). The Rowland universal dementia assessment scale (RUDAS): a multicultural cognitive assessment scale. International Psychogeriatrics, 16(1), 13-31.

Svennevig, J. \& Landmark, A. M. (2019). Accounting for forgetfulness in dementia interaction. Linguistics Vanguard 5.

Svennevig, J. \& Lind, M. (2016). Dementia, interaction, and bilingualism: An exploratory case study. In Enger, H. O. et al. (eds.), Helt fabelaktig! Festskrift til Hanne Gram Simonsen på 70-årsdagen, p. 199-218. Oslo: Novus. 


\begin{tabular}{|c|c|}
\hline \multicolumn{2}{|c|}{ Appendix : Transcription symbols } \\
\hline[ & Beginning of overlapping talk \\
\hline ] & End of overlapping talk \\
\hline$(0.4)$ & Silence in seconds and miliseconds \\
\hline$()$. & A micropause less than 0.2 seconds \\
\hline . & Falling intonation \\
\hline , & Continuing intonation \\
\hline$?$ & Rising intonation \\
\hline wo: : : rd & Sound stretching \\
\hline Word & Stress \\
\hline wor- & Cut-off \\
\hline${ }^{\circ}$ word ${ }^{\circ}$ & Quieter talk \\
\hline hh hh & Laughter \\
\hline. $\mathrm{hh}$ & Inbreath \\
\hline (word) & Uncertain identification of word \\
\hline$(($ word $))$ & Transcriber comment \\
\hline
\end{tabular}




\section{Acknowledgements}

We thank the participants pseudonymised as Sven, Koki, Gabriel, Rey, Laura and JJ, their families and three health care professionals for participating in this study. We are grateful to the Anne-Brita Knapskog at Oslo University Hospital as well as three adult day care centers and several home nurses for help with recruitment. We would furthermore like to thank Ingeborg Sophie Ribu, Maria Njølstad Vonen and Malene Bøyum for assistance with the data collection, transcription and analyses, and Sarah Cameron for scoring of the Flanker results. Marianne Lind was involved in the study design, and provided helpful feedback to the manuscript. This work was partly supported by the Research Council of Norway through its Centres of Excellence funding scheme, project number 223265, as well as through project number 250093. 